\title{
Indeterminaciones y espacios vacíos en Roman Ingarden y Wolfgang Iser
}

\author{
Angélica TORNERO \\ Universidad Autónoma del Estado de Morelos \\ Universidad Nacional Autónoma de México
}

\section{Introducción}

En los albores del siglo XX, en las teorías de los formalistas rusos, se observa ya cierta base fenomenológica, en aspectos como la concepción de la evolución literaria como desplazamiento de sistemas o el mecanismo de desautomatización y el consecuente efecto de extrañamiento. ${ }^{1}$ Hay, también, en las propuestas del estructuralismo checo de la Escuela de Praga, con Jan Mukarovski, como principal exponente, cierta base en este sentido. Mukarovski desarrolla un modelo general ternario de comunicación, constituido por la relación de emisor, mensaje, receptor. Con este modelo busca determinar la obra literaria como un sistema de signos, con función estética (Mukarovsky, 1977). ${ }^{2}$ Para no ir muy lejos, Alfonso Reyes configura su teoría literaria con una base indiscutiblemente fenomenológica. No es éste el espacio para analizar las relaciones entre la fenomenología y las propuestas de la teoría literaria - formalistas y semióticas - desarrolladas a lo largo del siglo pasado; no obstante, es una línea de estudio interesante que conviene no abandonar si deseamos comprender más detalladamente la serie de intrincadas relaciones que configuran el mapa de la teoría literaria del siglo XX.

Fue el polaco Roman Ingarden el primero en hacer un estudio fenomenológico de la obra literaria, a partir de los desarrollos de Husserl, su maestro en Gotinga. Ingarden optó por esta vía con el afán de encontrar una alternativa a los enfoques prevalecientes en su época, con los cuales no comulgaba.

' V. Shklovski publica en 1917 "El arte como artificio". J. Tinianov publica en 1927 "Sobre la evolución literaria".

${ }^{2}$ Mukarosvki retoma de la teoría de Ingarden la idea de la concretización desde otra perspectiva. El proceso de concretización no se produce sólo en el nivel individual, se trata también de un proceso histórico en el que intervienen colectividades. Para Mukarovski el objeto de investigación no es el texto sino su actualización (Mukarovsky', 1977). 
El enfoque fenomenológico de origen husserliano fue retomado por Iser en la década de los setentas, en el marco de los trabajos de la Escuela de Constanza, relacionados con la estética de la recepción. Sus detalladas descripciones sobre el acto de lectura del texto literario han sido muy apreciadas y han marcado un importante camino en la que Darío Villanueva (1994: 171) llama la tercera vía, la recepción literaria, que incluye la perspectiva del lector.

Los desarrollos de Iser tienen sus antecedentes, por una parte, en el planteamiento de Ingarden y, por otra, en los desarrollos de la Escuela de Praga, con Mukarovsky y Vodicka. El autor ha abrevado de ambas fuentes para hacer su propuesta. La estética de la recepción, cuyo origen se relaciona con la Escuela de Praga (Warning, 1989: 15), aleja a Iser de Ingarden, de manera importante; no obstante, es innegable la deuda que este autor tiene con el discípulo de Husserl.

Este ensayo tiene como objetivo presentar tres aspectos centrales de los desarrollos de Roman Ingarden y Wolfgang Iser: indeterminación, espacios vacíos y concretización, en los que se ponen en evidencia de manera palpable las diferencias entre estos dos estudiosos de la literatura.

Iser ha retomado de Ingarden los aspectos indeterminación y concretización y les ha dado un giro importante. Para Iser, como se verá más adelante, la indeterminación, que él llama espacios vacíos, es el elemento principal de articulación entre texto y lector y no una fase en el proceso hacia las cualidades metafisicas, como en el caso de Ingarden (Warning, 1989).

La perspectiva del lector ha despuntado en los últimos treinta años y, aparentemente, no saldrá pronto de la escena de los estudios literarios. Hay puntos de esta perspectiva en los que es preciso seguir reflexionando. Estos aspectos destacados por la fenomenología de la literatura y la estética de la recepción, indeterminación, concretización, espacios vacíos, han sido y serán retomados, me parece, por aquellos interesados no sólo en estos ámbitos de la teoria literaria, también por quienes han optado por aproximaciones como la semiótica, la pragmática y la hermenéutica, entre otras.

\section{La concretización de las indeterminaciones como actitud estética}

En La obra de arte literaria (1931), Roman Ingarden discute, inicialmente, dos tendencias teóricas, desarrolladas en su época, en el ámbito de los estudios literarios. Por un lado, critica el "neopositivismo", el cual postula que la obra literaria es igual al fenómeno físico, lo que supone que se reduce a letras sobre papel. El segundo es el enfoque psicologista, el cual supone que la obra no puede ser objeto de investigación científica porque se realiza sólo en cuanto el sujeto la experimenta (Ingarden, 1998: 35). 
La fenomenología abre una posibilidad distinta a Ingarden para pensar la obra literaria. A la luz de las consideraciones husserlianas, el autor se pregunta, ¿cómo está estructurado este objeto de conocimiento? Ésta es la pregunta inicial que guía la investigación. Este objeto del conocimiento tiene una estructura que es preciso descubrir para responder una segunda cuestión, ¿cómo existe?

El autor parte de dos ideas fundamentales: la obra de arte literaria (1) es un objeto (2) complejamente estratificado o multiestratificado. Ésta es la naturaleza de la obra de arte literaria; los estratos en su conjunto son su esencia. Ingarden distingue cuatro estratos: 1) estrato de los sonidos verbales, 2) estrato de las unidades de sentido, 3) estrato de los objetos representados y 4) estrato de los aspectos esquematizados.

Para Ingarden, la obra de arte literaria es una formación puramente intencional, que tiene origen en los actos creativos de la conciencia del autor y fundamento físico en el texto, fijado por la escritura. Por virtud de este estrato dual (sonido y sentido) la obra es intersubjetivamente accesible y reproducible, tanto como llega a ser un objeto intersubjetivo intencional, relacionado con una comunidad de lectores $(36){ }^{3}$

Esta estructura esencial de la obra literaria no se realiza si no es concretizada por el lector. En este sentido, la tarea de Ingarden consiste en confrontar la estructura del texto literario con las formas en que puede ser concretizado. De aquí deriva una consideración más: la obra literaria se compone de dos polos: el artístico y el estético. El primer se refiere al texto creado por el autor y el segundo, al creado por el lector. De esta distinción se desprende que la obra literaria no puede ser idéntica sólo al texto o sólo a la lectura: existe como oscilación entre ambos polos (Iser, 1987a: 215).

Ingarden heredó a la estética de la recepción los aspectos "puntos de indeterminación" y "concretización". Es quizá éste el legado más importante del discípulo de Husserl a los desarrollos de Iser. Éstos aparecen esbozados en los dos primeros estratos, no obstante alcanzan su contorno específico en los dos últimos.

\footnotetext{
${ }^{3}$ Uno de los temas más importantes de la fenomenología de Husserl es la intencionalidad. La palabra intentio significa dirigirse a. Toda vivencia se dirige a algo. La percepción es, en cuanto tal, percepción de algo y lo mismo ocurre con la representación, el recuerdo, el juicio, la conjetura, la expectativa, la esperanza, el amor. Se trata de formas de conducta que se dirigen a algo (Szilasi, 1959: 32).

La percepción es desde su origen percepción de algo. En los objetos que percibimos hay algo que es su contenido y desempeña un papel en las sucesivas referencias sintéticas de mi existencia. No hay conciencia si no es conciencia de algo, si no se muestra en ella un determinado fenómeno. La conciencia es siempre una conciencia intencional, proyectada desde el fenómeno y es en el sujeto que lo experimenta donde el fenómeno obtiene su sola posibilidad de existencia y sentido.
} 
Ya en los planteamientos del primer estrato, Ingarden muestra su posición inicial en relación con las interrupciones o la discontinuidad, de la cual Iser se deslindará cuarenta años después. Los sonidos verbales, señala el autor, se organizan en palabras muertas - con lo que se refiere a los términos científicos artificialmente construidos-, "las cuales son del tipo menos apropiado para la obra de arte literaria" (Ingarden, 1998: 63), y en palabras vivas, las vibrantes y potentes, que se emplean en las conversaciones de la vida cotidiana. Estas palabras evocan en el oyente imágenes gráficas del objeto dado y pueden facilitar la compresión intuitiva.

Estos sonidos se organizan también como oraciones en las que se distinguen aspectos como el ritmo y el tempo. Ingarden caracteriza dos tipos de cualidades rítmicas: por un lado, las que requieren para su constitución de una repetición estrictamente regular de la misma sucesión de acentos y, por otro, aquellos para cuya constitución esta regularidad estricta no es incondicionalmente necesaria. Estos tipos de ritmos introducen el fenómeno fónico del tempo (68).

Es en esta distinción fundamental del ritmo donde Ingarden introduce el comentario que cuestiona el rasgo destacado por Iser años después. El autor polaco acepta que el ritmo en una obra literaria no tiene que ser el mismo en todas sus partes; "por el contrario, el cambio, dentro de ciertos límites, produce caracteres de un más alto grado" (68). No obstante, pone como condición que estos cambios no sean demasiado frecuentes; asume que las obras forman todos orgánicos y que el lector debe llenar sus indeterminaciones para completar la obra, aparentemente, en la armonía. Esto supone que hay una forma correcta de concretizar las indeterminaciones y esto es justamente lo que provoca la actitud estética. Más adelante se retoma este punto.

Del segundo estrato, el de las unidades de sentido, destaca la detallada exploración de las palabras, las oraciones, complejos de oraciones y la descripción de la forma en que éstas se entrelazan de modos diferentes para formar unidades más complejas de significados, que revelan estructuras como un relato, un poema, una novela. Al final del análisis, surge un mundo particular, como correlato puramente intencional de un complejo de oraciones. La suma de correlatos oracionales intencionales consecutivos la denomina "mundo presentado" en la obra. Tanto las palabras, como las oraciones y los conjuntos de oraciones "tienen" su correlato derivado puramente intencional; poseen una intencionalidad prestada que les es conferida por actos de conciencia.

El tercer y cuarto estratos son fundamentales para comprender los aspectos de indeterminación y concretización en Ingarden. Veamos sumariamente en qué consiste cada uno de ellos. El tercer estrato es en el que generalmente fijamos nuestra atención en el acto de lectura. En este estrato se ubica la gran mayoría de los estudios literarios; es el único factor de la obra de arte literaria que se 
comprende temáticamente. "En la medida en que en su lectura el lector sigue las intenciones de sentido del texto, los objetos representados siempre son lo primero que le llega a la atención en una simple lectura de la obra" (259).

Por objetos representados, Ingarden se refiere a todo lo que se representa como tal; abarca todo lo que nominalmente se proyecta, sea cual sea su categoría de objetividad o su esencia material. Se refiere tanto a cosas, a personas, a acontecimientos, ocurrencias, estados, actos realizados por las personas. Contiene, asimismo, lo que se intenciona con los verbos. Los objetos representados, lo mismo que las oraciones o complejos de oraciones, no yacen uno al lado de otro sin nexo alguno. Antes, se unen en una esfera multiforme; al hacerlo constituyen un segmento de un mundo todavía en gran parte indeterminado, cuyas fronteras no están claramente delimitadas.

El cuarto estrato es el de los aspectos esquematizados. Por aspectos esquematizados, Ingarden entiende aquello que un sujeto perceptor experimenta ante un objeto $y$, en cuanto tal, exige "una percepción concreta, $o$, al menos, un acto vivido de representación por parte del sujeto, para poder ser experimentados de modo concreto y efectivo" (Ingarden, 1989: 41). Cuando se da esta experiencia, los aspectos esquematizados cumplen su función de hacer aparecer un objeto que se percibe en ese momento.

El autor distingue formas de indeterminación y concretización en el estrato de los objetos representados y en el de los aspectos esquematizados. En el estrato de los objetos, nos encontramos con un punto de indeterminación cuando es imposible, sobre la base de los enunciados de la obra, decir si cierto objeto o situación objetiva posee determinado atributo. En este sentido, se denomina punto de indeterminación al aspecto del objeto representado que no está específicamente determinado.

La presencia de lugares de indeterminación es necesaria en toda obra literaria, ya que es imposible establecer con exhaustividad todas las determinaciones de los objetos individuales. En la palabra o frase no está definida intencionalmente la multiplicidad total de atributos (37). Esta multiplicidad de atributos está indicada pero no la totalidad de elementos que le pertenecen. En este sentido, en la obra literaria habrá necesariamente puntos de indeterminación; es parte de su modo de ser.

La presencia de estos puntos en el estrato de los objetos representados permite dos modos posibles de lectura. Primero, el lector intenta identificar los puntos de indeterminación como tales y dejarlos indeterminados con el fin de aprehender la obra en su estructura característica. Segundo, el lector pasa por alto los lugares de indeterminación y los rellena involuntariamente con determinaciones no justificadas por el texto (38). Según el autor polaco, la primera forma de lectura está más cercana a la actitud lectora del crítico literario, más 
bien, del que denomina lector esteta. Por un lado, al leer identificando los lugares de indeterminación para dejarlos tal cual, se obtiene una aproximación correcta a la obra literaria; por otro, la identificación de lugares de indeterminación puede constituirse en procedimiento para hacer estudios literarios. Por ejemplo, observar en un tipo de novela, digamos el género policiaco, el modo en que se realizan estos lugares de indeterminación, puede dar pauta para identificar el modo de ser de este tipo de novela. El segundo tipo de lectura aleja al lector de la posibilidad de asirse a lo que el texto "pone de manifiesto" a través de los aspectos y puede llevar a lecturas desacertadas.

En cualquiera de los dos modos de lectura identificados por Ingarden, el lector lleva a cabo el acto de "rellenar" estos puntos de indeterminación. A este rellenar, Ingarden lo denomina concretización de los objetos representados. Es decir, llama concretización al acto de completar diversos aspectos de las objetividades representadas, no determinadas en el texto mismo, mediante una comprensión "sobreexplícita" de las frases y de los nombres que aparecen en el texto (38). En este acto fundamental de la lectura tiene lugar la actividad co-creativa del lector.

El acto de concretización tiene, para Ingarden, la función primordial de eliminar los puntos de indeterminación. Este aspecto ha sido destacado por diversos estudiosos de la obra del autor polaco, generalmente, en sentido negativo; ha sido estipulado, si no como opuesto, por lo menos, contrario a la interpretación que Iser hace del concepto (Warning, 1989). La idea de las concretizaciones en Ingarden obedece más a la necesidad, al leer, de disolver estos puntos de indeterminación que a observarlos como elementos de articulación entre el texto y el lector, como lo hace Iser. A este último no le ocupa la eliminación o no de estos espacios; le interesa describir el mecanismo (espacios vacíos y concretizaciones) propio de la obra literaria, que se actualiza al momento de leer.

En este sentido, Ingarden señala que la concretización juega un papel primordial en la transición de la aprehensión extraestética de la obra a la aprehensión estética, de acuerdo con los siguientes aspectos. Primero, hay una aprehensión estética apropiada en la obra literaria, dada por la correcta concretización de los objetos ofrecidos en ella. Segundo, los lugares de indeterminación pueden ser llenados de distinta manera, conservando la armonía con el estrato semántico de la obra. Tercero, la configuración estética final de la obra puede sufrir modificaciones, debidas o a las concretizaciones diferentes, lo cual puede ser ventajoso o perjudicial para el valor de la obra global. Cuarto, las cuestiones relativas a la aprehensión estética adecuada de la obra y de su correcta valoración están en estrecha conexión con el problema de la concretización de la obra (46-47).

Las concretizaciones sucederán, así, de manera correcta o incorrecta de acuerdo con las habilidades del lector para actualizar los aspectos sugeridos en 
el texto y sus formas de "rellenarlos". Pero hay algo más. Ingarden investiga si el estrato de los objetos "hace algo" en la estructura de la obra de arte misma, por lo cual otro elemento emerge en ella, o si su papel se agota en su mera presencia (Ingarden, 1998: 340). Tras ciertas consideraciones, el autor llega a la conclusión de que en efecto, el estrato "hace algo", es decir, tiene una función que consiste en manifestar las cualidades metafísicas.

Las objetividades representadas tienen como función primordial exhibir y manifestar estas cualidades metafísicas, pero no por sí mismas. Su manifestación depende de las objetividades representadas y de la estructura y la cooperación de todos los estratos de la obra de arte literaria. Esto muestra, dice Ingarden (349), que a pesar de la estratificación, la obra sigue siendo una unidad orgánica.

Las cualidades metafísicas pueden ser manifestadas solamente por la concretización de la obra en la lectura. Estas cualidades, así como la manera de su manifestación en la concretización, constituyen una totalidad estética.

$\mathrm{Al}$ abordar el aspecto de las concretizaciones en el estrato de los aspectos esquematizados, el autor polaco observa que éstas ocurrirán de manera distinta entre un lector y otro. El estrato de los aspectos juega un papel importante, en este sentido, ya que el valor estético se constituye en las concretizaciones realizadas en relación con los aspectos. Es decir, el modo en que tiene lugar la concretización y la actualización en este estrato es cardinal para la aprehensión estética de la obra literaria (Ingarden, 1989: 40).

El lector completa los aspectos con detalles que corresponden a sus hábitos de percepción, sensibilidad y sus preferencias por ciertas cualidades y relaciones, lo cual supone que hay diferencias de un lector a otro. A pesar de estas diferencias, Ingarden insiste en que las concretizaciones sucederán de manera correcta o incorrecta, dependiendo de la "preocupación" del lector por la reconstrucción fiel de la forma propia de la obra (44).

Cuando el análisis de la reconstrucción desemboca en la cuestión del valor artístico, la metafísica en la concepción estética de Ingarden se hace más evidente. Por valor artístico Ingarden entiende el que está en la obra misma y por valor estético el que se da a partir de las concretizaciones (estéticas) que hace el lector (48). Al caracterizar el primero, Ingarden pone en evidencia estos rasgos metafísicos en su estética: el valor artístico es un medio necesario para "la actualización de algo que es valioso en y por sí mismo, y en este sentido es absoluto, y que presta un valor a cualquier cosa que lo condicione como tal" (49). El lector esteta será aquel que actualice "lo que es valioso"; aquel que lea identificando indeterminaciones como parte de la propuesta estética de la obra, sin intentar explicarlas, por lo tanto, aquel que lea "correctamente"; aquel que concretice de manera que el valor estético consista en alcanzar esas cualidades metafísicas que exhibe el estrato de los objetos representados. 
Aparentemente, para Ingarden en el proceso de lectura se llega a las concretizaciones por las determinaciones y no por las indeterminaciones. Cuando el texto se excede, como lo vimos en el caso del estrato fónico, en sus indeterminaciones, no es posible llegar a la armonía polifónica, a la perfección de la obra.

\section{Los espacios vacios como elementos de articulación entre texto y lector}

Desde sus primeros trabajos, el alemán Wolfgang Iser pone en evidencia su interés por la comunicación. La crítica central del autor a otros enfoques de la recepción radica precisamente en el modelo de comunicación sugerido. Las teorías de la recepción de cuño marxista, elaboradas en la República Democrática Alemana, dice Iser, sugieren que la comunicación es sólo representable en una vía, del texto al lector. No obstante, argumenta, las estructuras de los textos adquieren su finalidad en cuanto son capaces de producir actos en cuyo desarrollo tiene lugar una traducibilidad del texto en la conciencia del lector (Iser, 1987b: 176).

Al igual que Ingarden, Iser se interesó por describir los actos que la conciencia realiza al momento de confrontarse con el texto literario. El texto no es el que suministra al lector y éste recibe pasivamente sus contenidos; se puede decir que éste inicia la transferencia, la cual se logra sólo por los actos que reclaman aptitudes de la conciencia.

En El acto de leer (1976), Iser describe de manera exhaustiva el proceso de lectura. Su reflexión comienza con una distinción en torno de la percepción del objeto descrita por Husserl. Según Iser, el texto difiere del objeto de la percepción, ya que éste se presenta como un todo ante la mirada y un texto sólo puede abrirse como objeto en la fase final de la lectura (177). Mientras que el objeto siempre lo tenemos enfrente, en el texto estamos inmersos. Al ser esto así, en la relación texto y lector se da un modo de comprensión diferente al del proceso de percepción del objeto.

El concepto de indeterminación no es en Iser, como lo fue en Ingarden, un hallazgo, producto de su reflexión fenomenológica. Para realizar su análisis, Iser tiene ya en mente el término acuñado por Ingarden, aunque después modificará su comprensión Esto es evidente desde el inicio. En sus primeras consideraciones relacionadas con la dialéctica entre protención y retención, Iser apunta a la conformación de lo que más adelante llamará "espacios vacíos", con lo cual se alejará de sentido de indeterminación en Ingarden. Esta misma dialéctica y las demás condiciones formales que hacen aparecer en el texto los espacios vacíos, preparan el terreno para uno de los aportes fundamentales de Iser, la experiencia ajena, la del otro que está siendo representado, y que es introducida en la propia. 
La primera distinción que hace Iser para explicar este modo de comprensión es lo que denomina el "punto de visión móvil". El lector se mueve, como punto de perspectiva, a través del ámbito de los objetos; el lector es un punto que se desplaza en el texto y va actualizando sus distintas fases. En estas fases está presente el carácter de objeto del texto, "pero a la vez aparece como inadecuado, pues el carácter siempre es algo más que lo que el lector es capaz de actualizar de él en el tramo correspondiente del momento de lectura" (178). El carácter del objeto del texto literario no es igual a las manifestaciones en el flujo de la lectura. Este carácter se da mediante síntesis. Así, "el carácter de objetividad del texto comienza a construirse como un correlato de la conciencia por medio de la secuencia de la síntesis" (179).

Para explicar la conformación del correlato de la conciencia, Iser acude al desarrollo de Ingarden, relacionado con los correlatos intencionales de la frase. Como se vio arriba, Ingarden, en el estrato de las unidades de sentido, describe detalladamente cómo los texto de ficción se construyen a partir de los correlatos intencionales de la frase, desde luego que tienen lugar en el lector, que activa el concierto de estos correlatos.

Para explicar el proceso del punto de visión móvil y de la secuencia de síntesis a partir del correlato intencional de la frase, el autor alemán acude a los conceptos husserlianos de protención y retención. ${ }^{4}$ En cuanto al primero, dice Iser, "el haz semántico de la dirección de cada frase siempre implica una expectativa que apunta a lo que viene". Husserl ha denominado a estas expectativas protenciones (181). El autor afirma que esta estructura es propia del correlato de la frase de los textos de ficción. La consecuencia de una estructura como ésta en estos textos es menos la de cumplir la expectativa que la de modificarla ininterrumpidamente. Es decir, en el texto de ficción de lo que se trata es de que la expectativa que el lector se genera no se cumpla, sino se modifique constantemente.

Lo que hemos leído se sumerge en el recuerdo y palidece frente a un horizonte de vacío, creado por la expectativa, que figura en un marco general con

${ }^{4}$ Las cosas no se presentan nunca a la conciencia en su totalidad, "sino a través de meros matices o escorzos de ellas" (Husserl, 1985: 96). Lo que observamos de las cosas es una realidad múltiple que, en un primer golpe de vista, aparece como visión global. Ahora bien, lo que observamos de la cosa observada se destaca en un fondo; cada cosa remite a un horizonte externo y a la vez se realiza en un horizonte interno. Además, lo observado de la cosa observada es mirado por mí. En ese mirar la cosa se me presentan todos los recuerdos; a este fenómeno de la memoria actual e implícita, Husserl lo llama retención. El recuerdo no es posible sino gracias a la retención, de la cual recibo o de la cual extrae los objetos que recuerda. Destaca también el fenómeno del porvenir; hay expectativa en relación con lo observado de la cosa. A esto Husserl lo denominó protenciones. Por último, la cosa observada está inserta en determinado lugar en la historia. 
respecto de lo mantenido en la retención. Conforme avanzamos en la lectura, lo que permanece en la retención se anima y lo recordado se sitúa ante un nuevo horizonte que no existía cuando fue captado. En este sentido, cada instante de lectura es una dialéctica de protención y retención. Se transmite un horizonte de futuro, todavía vacio, pero que debe ser colmado con un horizonte de pasado, saturado pero continuamente palideciente (181-182).

De las modalidades que caracterizan la condición del correlato del texto en la conciencia, producido en el proceso de lectura, destaca el aspecto, retomado de Ingarden, relacionado con el entorpecimiento que impide la realización sin dificultades entre protención y retención. El autor polaco se refirió a esta perturbación, a estos hiatos, como deficiencia. La idea de armonía en Ingarden se relaciona con una continuidad en el flujo que al ser interrumpida genera malestar y debe ser superada. Según Iser, esto habla de su adhesión a la idea clásica del arte (Iser, 1987a: 222). Para Iser, en los textos literarios se espera ese tipo de giros; estas sorpresas. Debido a estos "vericuetos inesperados" que frustran las expectativas, el relato alcanza su dinamismo.

Estos hiatos tienen una función decisiva, pues "por su medio tiene lugar una demarcación entre los correlatos de la frase" (184). En la novela que recurre al estilo indirecto, las marcas para mostrar una frase, como la expresión de un personaje, son poco acentuadas, incluso desaparecen. La diferenciación se da a partir de las demarcaciones posibles por los hiatos. Las frases están situadas en perspectivas que ellas mismas trazan, el punto de visión móvil, en cada instante de lectura, se encuentra también en una determinada perspectiva (184).

La demarcación articula los momentos de lectura. Ahora bien, para que esto sea posible, el instante de la situación anterior de perspectiva del punto de visión móvil permanece presente retencionalmente; sólo así se marca la diferencia de perspectiva. Iser abunda, aquí no lo haremos, en la forma en que esta perspectiva se diversifica y las relaciones realizadas por el lector.

La constitución de la consistencia, como correlato del punto visión móvil, resulta de la interacción entre texto y lector; no se reduce exclusivamente a signos en el texto ni a las aptitudes del lector. Se efectúa en la sucesión de agrupaciones de figuras de signos, que establecen relaciones entre sí y son identificadas por el lector.

La constitución de la consistencia ocurre en oposición a la apertura del texto y se relaciona con la necesidad de cerrar la figura. Esta constitución es fundamento para los actos de comprensión.

Pero el proceso de lectura es mucho más complejo. El lector se encuentra, frente al texto literario, en un continuo proceso de opciones mediante las que se realizan selectivamente las posibilidades de conexión (153). Esto significa que el lector, a partir de las relaciones de las figuras de signos, está en posibilidad de 
seleccionar para realizar la constitución del objeto imaginario. Esta oscilación del lector, entre hallarse asido y distanciado, produce el conflicto.

Estos conflictos se amortiguan si ocasionan una tercera dimensión que nace justo de la oscilación del lector, al experimentar el texto como acontecimiento. Iser dice: "el carácter de acontecimiento es un correlato central de la conciencia del texto, que nace de la irritación de la constitución de la consistencia, producida por las estrategias del texto" (207).

El acontecimiento, en mayor o en menor medida, es apertura que permite al lector buscar la coherencia. Esta búsqueda es un proceso vivo. El lector necesita alcanzarla para lograr la comprensión, aunque sea momentáneamente, debido a que su expectativa se frustrará enseguida.

El texto no es espera ni recuerdo, de modo que la dialéctica protención-retención produce la síntesis de la representación. Para abordar este aspecto, Iser retoma la terminología de Husserl: síntesis pasivas. Éstas se distinguen de los juicios y predicaciones; son síntesis pre-predicativas, que se producen debajo del umbral de la conciencia.

Durante la lectura nos encontramos sumidos en la actividad sintética. El modo central de las síntesis es la imagen, que muestra algo diferente del objeto empírico y del significado de un objeto representado. Esta imagen se caracteriza por hacer aparecer aspectos que no se imponen en la percepción directa. Cuando leemos el texto literario no percibimos de manera directa los objetos; antes nos hacemos una representación de ellos. Ahora bien, la imagen se encuentra en permanente movimiento durante la lectura, por lo que la representación se constituye mediante facetas diferentes. Elevar esto diferente a imagen es el acto sintético de la representación que discurre como síntesis pasiva, en tanto en ninguno de sus pasos tiene lugar una predicación explícita.

Iser define el texto como secuencia de esquemas que guían la actividad representativa del lector. Al llegar a este punto, retomando a Ingarden, Iser dice que los aspectos esquemáticos del texto se limitan a hacernos saber en qué condiciones debe ser constituido el objeto imaginario. Y, como lo hace Ingarden, Iser señala que son las indeterminaciones, que él llama espacios vacíos, las que movilizan la imaginación para producir el objeto imaginario como correlato de la conciencia representativa (Iser, 1989: 155).

Pero, a diferencia de Ingarden, para Iser los espacios vacios son condiciones de comunicación porque activan la interacción entre texto y lector, y la regulan hasta un cierto grado (Iser, 1987: 281). Los espacios vacíos son, en este sentido, condición de posibilidad de que el lector ocupe un espacio en el texto por medio de sus represtaciones. Para Ingarden, los puntos de indeterminación son más una carencia de determinación, es decir, una falta, que un poder-ser.

Por medio de los espacios vacíos queda marcado el potencial de ensamblaje 
de los segmentos del texto que ha sido dejado en blanco; en este sentido, los espacios vacíos materializan las articulaciones del texto.

Iser se basa en algunos supuestos de la teoría pragmática de la comunicación para explicar el funcionamiento de la interrupción en el texto literario. En primer lugar, el autor señala que los espacios vacíos como interrupción del potencial de ensamblaje se convierten en criterios para diferenciar el uso del lenguaje cotidiano del de ficción. En el habla cotidiana se intenta difuminar la interrupción, limitar la pluralidad de posibilidades de lo comunicado; en los textos de ficción, es al contrario, el potencial de ensamblaje interrumpido por los espacios vacíos abre una pluralidad de posibilidades.

Una segunda consideración derivada de esta teoría es que en el acto de lectura del texto literario no existe una situación dada de comunicación en la cual se inserte el lector. Antes, esta situación la constituye el propio lector en el proceso de co-creación de la obra, gracias a esta interrupción del potencial del ensamblaje.

En tercer término observa que en un texto literario las normas despragmatizadas han perdido su forma habitual de conexión. La despragmatización se señala en el texto como espacio vacío, que en el mejor de los casos sugiere posibilidades del potencial de ensamblaje. A la vez, en las interrupciones se liberan espacios vacios que orientan las posibles combinaciones que realizará el lector. Estos espacios vacíos no se ocultan sólo en el repertorio, conjunto de normas del texto, sino también en las estrategias literarias.

Cuando los espacios vacíos interrumpen el potencial de ensamblaje, el proceso de concretización alcanza su desarrollo en la capacidad imaginativa del lector.

Una consideración más, derivada de esta reflexión, es que los esquemas del texto que sirven para la constitución de las representaciones raramente obedecen al principio de continuidad fluida (Iser, 1987b: 284). Al contrario, la elevada estructuración del texto literario lleva a la transgresión. Los espacios vacíos, a partir del proceso referido, suprimen la expectativa de esta continuidad.

Es aquí, en este proceso, donde aparece, para Iser, la relevancia estética del espacio vacío (285). Los espacios vacíos al provocar la colisión en las representaciones se vuelven estéticamente relevantes. La relevancia estética radica principalmente en que el lector, al leer el texto literario y entrar en el proceso de colisión de su representación por la interrupción de la continuidad fluida, pone en marcha una interacción específica de sus representaciones, guiada por el texto. El lector, mediante sus cambiantes reorientaciones, logra representarse aquello que le había quedado oculto. "La perturbación de la representación releva al lector de sus disposiciones habituales con el fin de que sea capaz de representarse lo que parecía quizá irrepresentable en razón de las decisiones 
de sus orientaciones habituales" (289). Esta operación conduce al lector a tomar distancia de sí mismo y a observar sus propias producciones. La toma de distancia, a su vez, permite al lector, la interpretación.

Iser concluye, en este sentido, que si la interrupción de la continuidad fluida condiciona la actividad representadora, entonces los espacios vacíos se muestran en el texto como una condición de comunicación elemental (289).

No termina aquí el amplio desarrollo que el autor hizo en relación con los espacios vacíos y las llamadas negaciones (una variación de espacio vacío); no obstante, es imposible abarcar estas consideraciones. Baste con lo aquí expuesto para tener una idea, lo más cercana posible, a la configuración del aspecto espacios vacíos, del autor alemán, y sus diferencias con el aspecto ingardeniano de concretización de los puntos de indeterminación.

\section{Consideraciones finales}

Aun cuando los enfoques de ambos autores se enmarcan en la fenomenología, describen el acto de lectura de manera distinta, a partir, principalmente, de la diferencia de apreciación entre los aspectos: puntos de indeterminación y espacios vacíos.

Las nociones de indeterminación y concretización conducen, en Ingarden, como se ha dicho ya, a consideraciones de tipo metafísicas. En el caso de Iser, en las consideraciones sobre los espacios vacíos prevalece la idea de articulación entre texto y lector, desarrollada con base en el enfoque de la pragmática. Ambos se ubican en una perspectiva estética; no obstante, lo hacen de manera diferente. Ingarden parece sostener resabios de la metafisica contra la que el siglo $\mathrm{XX}, \mathrm{y}$ lo que va de éste, ha luchado denodadamente. Iser, más actual, incluye, a su modo, décadas de reflexión en torno a los inconvenientes de la metafísica, como la han entendido los detractores más acedos; integra, desde su comprensión, las meditaciones de la deconstrucción, el postestructuralismo, la pragmática, las actuales teorías de los actos y del juego, incluso, la teoría de sistemas. De ahí que esta propuesta nos resulte más reveladora, operativa, acertada como punto de partida de nuestras propias reflexiones.

Hay, no obstante, una consideración importante que resulta de la lectura atenta de las propuestas de estos dos autores. Uno puede pensar, hipotéticamente, claro, que la diferencia entre sus enfoques obedece a las distintas experiencias que tuvieron al confrontar la obra literaria, la estructura esencial de las obras literarias que leyeron, con su propia lectura. Estas experiencias lectoras están marcadas no sólo por sus propias circunstancias, sino por el tipo de obra que interesa a cada uno. Ingarden se centró para realizar sus reflexiones en el clasicismo; Iser trabajó, principalmente, la novela del siglo XVIII en adelante. La pregunta 
obligada es: ¿no será que los autores han descrito determinada obra literaria, es decir, la que correspondió a sus intereses, y no todas las obras literarias?

Sea como fuere, los autores, a través de sus interesantes reflexiones, nos ofrecen, por un lado, posibilidades de seguir pensando en los caminos de la teoría literaria, en sus límites y futuro, a la luz de las nuevas maneras de comprender a la misma teoría y las prácticas lectoras. Por otro lado, nos muestran que el camino de la reflexión sobre el texto literario no es un fluido continuo, sino una constante interrupción provocada por la búsqueda, a manera de variaciones, que distingue a este tipo de textos.

Obras citadas

INGARDEN, Roman. 1998. La obra de arte literaria. México: Taurus / UIA. . 1989. "Concreción y reconstrucción". Rainer WARNING, ed. Estética de la recepción. Madrid: Visor.

ISER, Wolfgang. 1989. "La estructura apelativa de los textos". Rainer WARNING, ed. Estética de la recepción. Madrid: Visor. . 1987a. "El proceso de lectura: enfoque fenomenológico". José Antonio MAYORAL, comp. Estética de la recepción. Madrid: Arco Libros. . 1987b. El acto de leer. Teoría del efecto estético. Madrid: Taurus.

MUKAROVSKY, Jan. 1977. Escritos de estética y semiótica del arte. Barcelona: Gustavo Gilli.

SzILASI, Wilhelm. 1959. Introducción a la fenomenología de Husserl. Buenos Aires: Amorrortu.

VILLANUEVA, Darío. 1994. "Fenomenología y pragmática del realismo literario". D. VILlanueVA, comp. Avances en teoría de la literatura. Santiago de Compostela: Universidad de Santiago de Compostela.

WARNING, Rainer. 1989. "La estética de la recepción en cuanto pragmática en las ciencias de la literatura”. Rainer WARNING, ed. Estética de la recepción. Madrid: Visor. 